\title{
A Distinct Contribution of Short-Wavelength-Sensitive Cones to Light-Evoked Activity in the Mouse Pretectal Olivary Nucleus
}

\author{
Annette E. Allen, Timothy M. Brown, and Robert J. Lucas \\ Faculty of Life Sciences, University of Manchester, Manchester M13 9PT, United Kingdom
}

\begin{abstract}
Melanopsin-expressing intrinsically photosensitive retinal ganglion cells (ipRGCs) combine inputs from outer-retinal rod/cone photoreceptors with their intrinsic phototransduction machinery to drive a wide range of so-called non-image-forming (NIF) responses to light. Defining the contribution of each photoreceptor class to evoked responses is vital for determining the degree to which our sensory capabilities depend on melanopsin and for optimizing NIF responses to benefit human health. We addressed this problem by recording electrophysiological responses in the mouse pretectal olivary nucleus (PON) (a target of ipRGCs and origin of the pupil light reflex) to a range of gradual and abrupt changes in light intensity. Dim stimuli drove minimal changes in PON activity, suggesting that rods contribute little under these conditions. To separate cone from melanopsin influences, we compared responses to short $(460 \mathrm{~nm})$ and longer $(600 / 655 \mathrm{~nm})$ wavelengths in mice carrying a red shifted cone population $\left(O p n 1 m w^{R}\right)$ or lacking melanopsin $\left(0 p n 4^{-1-}\right)$. Our data reveal a surprising difference in the quality of information available from medium- and short-wavelength-sensitive cones. The majority cone population (responsive to 600/655 nm) supported only transient changes in firing and responses to relatively sudden changes in light intensity. In contrast, cones uniquely sensitive to the shorter wavelength (S-cones) were better able to drive responses to gradual changes in illuminance, contributed a distinct off inhibition, and at least partially recapitulated the ability of melanopsin to sustain responses under continuous illumination. These data reveal a new role for S-cones unrelated to color vision and suggest renewed consideration of cone contributions to NIF vision at shorter wavelengths.
\end{abstract}

\section{Introduction}

A specialized subset of mammalian retinal ganglion cells are intrinsically photosensitive thanks to their expression of melanopsin ( $\mathrm{Lu}-$ cas et al., 2003). The anatomy and physiology of these intrinsically photosensitive retinal ganglion cells (ipRGCs) appears optimized for measuring ambient illumination. Accordingly, they are especially important for a range of so-called non-image-forming (NIF) light responses, including circadian photoentrainment and the pupil light reflex (Bailes and Lucas, 2010).

ipRGCs receive signals from the outer retina (Belenky et al., 2003; Tu et al., 2005; Wong et al., 2007; Schmidt et al., 2008), raising the question of under what circumstances NIF responses rely on conventional rods/cones as opposed to melanopsin photoreception. The current view is that responses driven by melanopsin occur at higher levels of illumination than those driven by rods (Lucas et al., 2003; Panda et al., 2003) and are more sustained than those driven by cones (Dkhissi-Benyahya et al.,

\footnotetext{
Received May 19, 2011; revised Aug. 16, 2011; accepted Aug. 18, 2011.

Author contributions: A.E.A., T.M.B., and R.J.L. designed research; A.E.A. performed research; A.E.A. and T.M.B. analyzed data; A.E.A., T.M.B., and R.J.L. wrote the paper.

This work was supported by the Biotechnology and Biological Sciences Research Council, the Your Manchester Fund, and the Wellcome trust.

This article is freely available online through the J Neurosci Open Choice option.

Correspondence should be addressed to Robert Lucas, Faculty of Life Sciences, AV Hill Building, University of Manchester, 0xford Road, Manchester M13 9PT, UK. E-mail: robert.lucas@manchester.ac.uk.

DOI:10.1523/JNEUROSCI.2505-11.2011

Copyright $\odot 2011$ the authors $\quad 0270-6474 / 11 / 3116833-11 \$ 15.00 / 0$
}

2007; Altimus et al., 2010; Lall et al., 2010; McDougal and Gamlin, 2010; Brown et al., 2011). It has therefore been predicted that melanopsin (and, at low light levels, rods) would be responsible for encoding absolute light levels (irradiance) and setting steadystate levels of activity in NIF centers. Conversely, cones would provide information about changes in relative light intensity and thus drive responses to temporal contrast.

Here we set out to test this basic model of cone and melanopsin contributions to NIF vision and to define the temporal frequency tuning of cone-dependent responses. To this end, we recorded electrophysiological activity in the mouse pretectal olivary nucleus (PON), a major central target of ipRGCs (Hattar et al., 2006) and the central origin of the pupil light reflex. Previous experiments describing luminance coding in this nucleus (Trejo and Cicerone, 1984; Clarke and Ikeda, 1985; Gamlin et al., 1995) predate the discovery of melanopsin, leaving unresolved the contribution of rods, cones, and melanopsin to this capacity. To address this problem, we used mice lacking either melanopsin $\left(O p n 4^{-l-}\right)$ or rods+cones $(r d / r d c l)$ and mice in which the mouse medium-wavelength-sensitive (MWS) cone opsin is replaced by the human red cone opsin (Smallwood et al., 2003). In these mice, termed Opn $1 m w^{R}$, cones that ordinarily express MWS opsin ( $>95 \%$ of the total) are anomalously sensitive to red light, allowing them to respond to "melanopsin-silent" longwavelength stimuli (Brown et al., 2010, 2011; Lall et al., 2010).

We find evidence that the population of MWS-expressing cones drives transient responses, tuned strongly toward sudden 
changes in illuminance, but that the small number of cones expressing only short-wavelength-sensitive (SWS) opsin (S-cones) support much more sustained activation and elicit responses over a wider range of temporal frequencies. Our findings are consistent with the general view that NIF responses are defined by separable "irradiance" and "contrast" signals dominated by melanopsin and cones, respectively. However, they reveal that S-cones can support sustained activation of the PON and define responses to even gradual changes in light intensity. If this unique S-cone contribution is replicated in other ipRGC-dependent systems, it could have important implications for the spectral sensitivity of NIF vision.

\section{Materials and Methods}

Animals. Mice were bred at the University of Manchester and housed under a $12 \mathrm{~h}$ light/dark cycle, with food and water available ad libitum. $O p n 1 m w^{R}, r d / r d c l$, and $O p n 4^{-1-}$ mice used were male, aged 3-5 months. Opn1mw $w^{R}$ and Opn $4^{-1-}$ had a mixed C57BL/6; 129sv strain background, and $r d / r d c l$ were $\mathrm{C} 3 \mathrm{H}$ strain. Note that $O p n 1 m w^{R}$ refers to the transgenic allele originally generated by Smallwood et al. (2003) and termed simply " $R$ " by them. All procedures conformed to requirements of the United Kingdom Animals (Scientific Procedures) Act, 1986.

In vivo neurophysiology. Mice were anesthetized with an intraperitoneal injection of urethane $(1.7 \mathrm{~g} / \mathrm{kg} ; 30 \% \mathrm{w} / \mathrm{v}$; Sigma-Aldrich $)$ and held in a stereotaxic frame (SR-15M; Narishige International). Subsequent injections of subcutaneous urethane $(10 \% \mathrm{w} / \mathrm{v})$ were administered as necessary. Pupil dilation was achieved through application of atropine (Sigma-Aldrich) to the stimulated eye. Mineral oil (Sigma-Aldrich) was also applied to each eye to retain corneal moisture. Throughout experimentation, core body temperature was maintained at $\sim 37^{\circ} \mathrm{C}$ via a homeothermic heat mat (Harvard Apparatus). The skull was exposed via a midline scalp incision, and a hole was drilled in the skull directly above the PON (mediolateral, $0.9 \mathrm{~mm}$; anteroposterior, $2.8 \mathrm{~mm}$, relative to bregma) according to a stereotaxic mouse atlas (Paxinos and Franklin, 2001). A 32-channel multiunit electrode (NeuroNexus Technologies) was used to record from the PON. This consisted of four silicon substrate shanks, $200 \mu \mathrm{m}$ apart and $5 \mathrm{~mm}$ long, with eight iridium electrode sites arranged vertically on each shank ( $413 \mu \mathrm{m}^{2}$ surface area, $50 \mu \mathrm{m}$ apart; A4X8-5 mm-50-200-413). A Recorder64 recorder system (Plexon) was used to acquire signals throughout experimentation. Signals were amplified by a $20 \times$ gain alternating current-coupled head stage (Plexon), followed by preamplifier conditioning, providing a total gain of $3000 \times$. Data were high-pass $(300 \mathrm{~Hz})$ filtered, and time-stamped neural waveforms were digitized simultaneously from all channels at a rate of $40 \mathrm{kHz}$ and stored for offline analysis.

Mice were left for $<1 \mathrm{~h}$ before recordings, to dark adapt and to allow neuronal activity to stabilize after electrode placement. Light stimuli were generated using a custom-made light source (Cairn Research) containing a blue $(460 \mathrm{~nm})$ and either red $(650 \mathrm{~nm})$ or orange $(600 \mathrm{~nm})$ LEDs (Cairn Research), fitted with appropriate bandpass filters (halfpeak width, $\pm 10 \mathrm{~nm}$ ). Light from LEDs was combined and subsequently passed through a filter wheel containing neutral-density filters (Cairn Research) and was focused onto a 5-mm-diameter circle of opal diffusing glass (Edmund Optics) placed $\sim 5 \mathrm{~mm}$ from the eye contralateral to the recording site. The diffuser was centered on the midpoint of the eye so that light would be distributed evenly across the retina. A National Instruments card (USB-6229) controlled by programs written in LabVIEW (version 8; National Instruments) was used to control stimulus intensity by altering LED output and to adjust the filter wheel. Stimuli were presented in order from dimmest to brightest. A period of $300 \mathrm{~s}$ darkness was allowed between stimulus presentations to minimize light adaptation.

Visual stimuli. Light was measured using an optical power meter (PM203 Optical Power Meter; Macam Photometrics) and spectrometer (Ocean Optics) or a spectroradiometer (Bentham Instruments). The effective quantal flux (in photons per square centimeters per seconds) of each stimulus for each opsin photopigment class was then estimated by weighting spectral irradiance according to pigment spectral efficiency using the following formula: effective photon flux $=\int P(\lambda) \cdot s(\lambda) \cdot l(\lambda) d \lambda$, where $P(\lambda)$ is spectral irradiance in photons per square centimeters per seconds per nanometers, $s(\lambda)$ is pigment spectral sensitivity approximated by the Govardovskii visual template (Govardovskii et al., 2000), and $l(\lambda)$ is mouse lens transmission as measured by Jacobs and Williams (2007). The spectral sensitivity of cone photoreceptors coexpressing SWS and MWS/red opsins was approximated by the linear sum of each pigment sensitivity curve weighted according to the relative expression of the two cone opsins and normalized to 1 at the wavelength of peak sensitivity.

For most experiments, short- and long-wavelength stimuli were matched according to their effective photon flux for the MWS pigment [or in the case of Opn1mw $w^{R}$ mice, the knocked-in long-wavelengthsensitive (LWS) cone pigment]. On this basis, the effective photon flux for 460 and $655 \mathrm{~nm}$ stimuli matched at 14.24 ( $\log _{10}$ effective photons/ $\mathrm{cm}^{2} / \mathrm{s}$ ) for LWS opsin was 11.6 and 4.8 , respectively, for SWS opsin, 14.7 and 12 for rod opsin, and 14.8 and 11.1 for melanopsin. In the case of $O p n 4^{-1-}$ mice, 460 and $600 \mathrm{~nm}$ isoluminant for MWS opsin at 14.24 $\log _{10}$ effective photons $/ \mathrm{cm}^{2} / \mathrm{s}$ would have effective photon flux of 14.3 and 12.5 for rod opsin, and 11.0 and 5.2 for SWS opsin, respectively.

In pupillometry experiments, a standard LCD computer monitor was used to generate near full-field illumination for one eye. Sinusoidal oscillations at $74 \%$ contrast, around a midpoint whose effective photon flux ( $\log _{10}$ photons $/ \mathrm{cm}^{2} / \mathrm{s}$ ) was 10.87 for SWS opsin, 13.10 for rod opsin, 13.18 for melanopsin, 13.03 for MWS opsin, and 12.74 for LWS opsin were then applied, and contralateral pupil responses were recorded.

Histology. To establish the location of recording sites, the recording electrode was dipped in fluorescent dye (Cell Tracker CM-DiI; Invitrogen) before insertion. At the end of recordings, animals were perfused with $0.9 \%$ saline, followed by $4 \%$ paraformaldehyde in $0.1 \mathrm{M}$ phosphate buffer $(\mathrm{PB})$. The brain was then removed and postfixed overnight in $4 \%$ paraformaldehyde, before cryoprotection for $24 \mathrm{~h}$ in $30 \%$ sucrose. Ninety-nine-micrometer coronal sections were then cut using a sledge microtome and were stored free floating in $0.1 \mathrm{M}$ PBS solution $(0.9 \%$ $\mathrm{NaCl}$ in $0.1 \mathrm{M} \mathrm{PB}$ ).

Expression of the calcium binding protein parvalbumin was used as a marker of PON neurons. Thus, sections were washed once in PBS solution and twice in PB-T $(0.3 \%$ Triton X-100 in $0.1 \mathrm{M} \mathrm{PB})$ and then incubated for $1 \mathrm{~h}$ in $2 \%$ normal horse serum (Vector Laboratories) prepared in PB-T. Sections were then incubated overnight in mouse antiparvalbumin primary antibody (1:8000; Sigma-Aldrich) prepared in $0.1 \%$ bovine serum albumin (prepared in $0.1 \mathrm{M} \mathrm{PB}$ ). Anti-parvalbumin antibody was washed from sections with PBS buffer. Sections were then incubated for $3 \mathrm{~h}$ in fluorescein horse anti-mouse fluorescent antibody (1:200; Vector Laboratories). Sections were mounted onto glass slides, and coverslips were applied using Vectashield (Vector Laboratories). Slides were visualized with an Olympus BX51 with appropriate filter sets. DiI clearly demarcated the position of electrode shanks in relation in brain sections, allowing the position of electrode sites to be estimated with good precision in the mediolateral and rostrocaudal planes. Position in the dorsoventral dimension was estimated by the depth of dye staining and accorded well with estimates based on micromanipulator extension, suggesting a resolution of $\sim 50 \mu \mathrm{m}$ in this dimension. The position of the PON in each section was then defined by parvalbumin staining and comparison with a mouse brain atlas (Paxinos and Franklin, 2001).

Analysis. Offline, neural waveforms were processed using Offline Sorter (version 2.8.8; Plexon). Cross-channel artifacts were identified and removed, and then each channel was analyzed separately. For each channel, single-unit spikes were detected and categorized based on the spike waveform via a principal component analysis, whereby distinct clusters of spikes were readily identifiable, which showed a clear refractory period in their interspike interval distribution. Single-unit and unclassified waveforms were also combined to form multiunit data for each channel. Single-unit and multiunit data were then further examined using NeuroExplorer (version 4.032; Nex Technologies) to generate peristimulus time histograms to evaluate changes in firing rate in different response epochs. Light-responsive units were identified as those that showed discernible peaks in peristimulus time histograms that exceeded the $99 \%$ confidence limits, calculated from a Poisson distribution based 

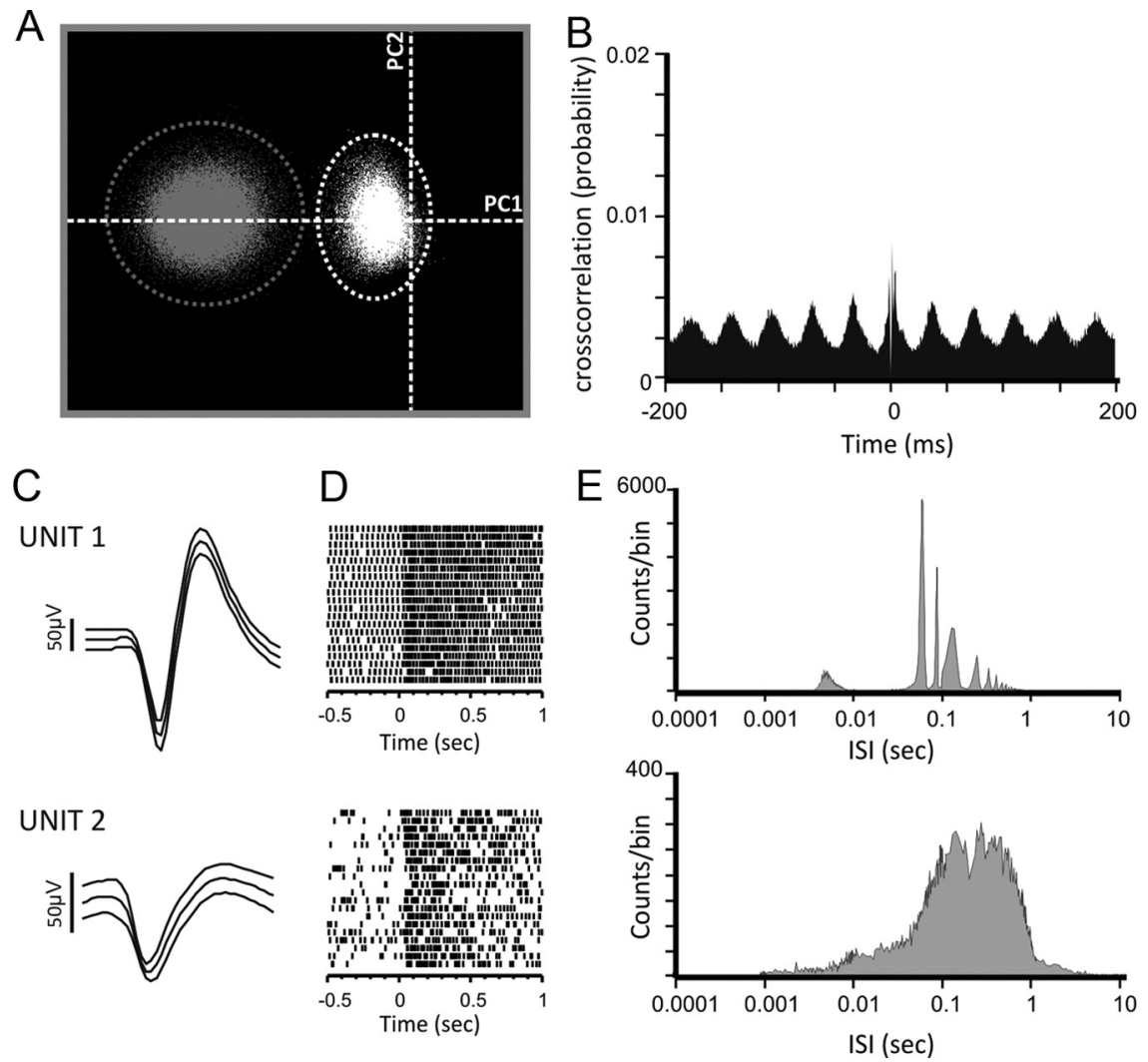

Figure 1. Identification of single units. $\boldsymbol{A}$, Representative scatter plot of spike waveforms plotted using the first two principal components (PC). Two clusters are readily identified (unit 1, gray; unit 2 , white). $x$-Axis, PC1; $y$-axis, PC2. For clarity, noise events are not plotted. $\boldsymbol{B}$, Pairwise comparison of each cluster through cross-correlation of spike times reveals no discernible relationship between spike firing in each cluster (probability of correlated firing $<0.01$ ). $C$, Mean \pm SD of spike waveform for the two units identified in $\boldsymbol{A}$. D, Raster plot showing the response of each unit to repeated $460 \mathrm{~nm}$ light pulses $\left(15.8 \log _{10}\right.$ photons $\left./ \mathrm{cm}^{2} / \mathrm{s}\right)$. E, Log interspike interval (ISI) for each unit. Unit 1 shows clear sharp peaks at discrete intervals, indicative of spikes fired in bursts. Comparatively, unit 2 shows a broad peak at longer interspike intervals, representative of tonic firing patterns. spike sorting (Fig. 1) and suggested that the vast majority of individual neurons responded either with "sustained" or "transient" increases in firing. In transient cells, firing rate increased at lights on and/or off but returned to baseline between, whereas sustained cells maintained elevated firing throughout light exposure. Sustained units were all found within or very close to the PON (as defined by parvalbumin immunoreactivity), in which they outnumbered transient cells 10:1 (Fig. 2C). Farther away from the PON, transient cells dominated, although cells showing sustained reductions in firing were occasionally encountered $(n=3)$. Given our interest in the PON, additional analysis was restricted to those sustained and transient cells found in or near this nucleus.

\section{Photoreceptive origins of the PON light response}

We next compared responses to $30 \mathrm{~s}$ blue $(460 \mathrm{~nm})$ and red $(655 \mathrm{~nm})$ stimuli over a range of irradiances. Replacement of the mouse MWS opsin $\left(\lambda_{\max }=511 \mathrm{~nm}\right)$ with the human LWS cone opsin $\left(\lambda_{\max }=556\right.$ $\mathrm{nm}$ ) in $O p n 1 m w^{R}$ mice ensures that, in this genotype, the longer wavelength robustly activates cones (and rods) but is essentially silent for melanopsin $\left(\lambda_{\max }=480\right.$ $\mathrm{nm})$. As such, by comparing responses to pairs of 655 and $460 \mathrm{~nm}$ stimuli set as isoluminant for LWS cone opsin, we hoped to reveal the extent to which cones (and by implication melanopsin) support PON light responses.

on prestimulus spike firing. Cells described as "sustained" cells were those having a significant elevation in firing rate in the last $10 \mathrm{~s}$ of a $30 \mathrm{~s}$, $460 \mathrm{~nm}$ high irradiance stimulus compared with prestimulus spike firing rate (two-tailed $t$ test; $p<0.05$ ). All data were then visualized and statistically examined using Office Excel (2003; Microsoft Corporation), GraphPad (version 4.02; GraphPad Software), and custom-made programs in MATLAB (r2008a; MathWorks).

\section{Results}

\section{"Sustained" and "transient" light responses in the} mouse pretectum

We initially set out to describe the response of neurons within the PON and surrounding pretectum of a visually intact mouse to a simple light pulse. For this purpose we used $O p n 1 m w^{R}$ mice. These animals carry a transgene that shifts cone spectral sensitivity but has no other known effects on cone function or connectivity (Smallwood et al., 2003; Jacobs et al., 2007). A $4 \times 8$ electrode array was introduced to a $350 \times 600 \mu \mathrm{m}\left(0.21 \mathrm{~mm}^{2}\right)$ area of the pretectum based on stereotaxic coordinates and near full-field $30 \mathrm{~s}$ pulses of a stimulus predicted to activate all known retinal photoreceptors $\left(460 \mathrm{~nm}, 15.8 \log _{10}\right.$ photons $\left./ \mathrm{cm}^{2} / \mathrm{s}\right)$ applied to the contralateral eye. The location of recording sites with respect to the anatomical PON (see Fig. $2 A, B$ ) was determined using the calcium binding protein parvalbumin as a marker for this brain region (Okoyama and Moriizumi, 2001).

Light induced a robust increase in multiunit activity across the mouse pretectum. Single units were readily identifiable after
Neither sustained nor transient units showed consistent responses to $460 \mathrm{~nm}$ stimuli at irradiances less than $\sim 11 \log _{10}$ photons $/ \mathrm{cm}^{2} / \mathrm{s}$ (Fig. $3 A, B$ ). Because pupil constriction in mice can be elicited by much dimmer stimuli (Pennesi et al., 1998; Lucas et al., 2003), this indicates either altered excitability of the PON in our anesthetized preparation or high sensitivity of the efferent limb of the pupil reflex to small changes in PON firing. In either case, our failure to record changes in firing rate at lower irradiances implies that any influence of rods on PON activity falls below the detection threshold of our methods.

Around response threshold, the change in firing rate elicited by cone-isoluminant 460 and $655 \mathrm{~nm}$ stimuli was similar (Fig. $3 A, B)$, indicating that cones define the sensitivity of the PON response as recorded here. However, at higher irradiances, we observed a large difference in the response of sustained but not transient neurons to 460 versus $655 \mathrm{~nm}$ light (Fig. 3). In particular, the long wavelength drove a transient "on" (and sometimes "off") excitation in the sustained population but not the characteristic tonic increase in firing observed under $460 \mathrm{~nm}$ (Fig. $3 A, B)$. These data are therefore consistent with the view that, in NIF centers, cones support phasic responses to lights on/off but cannot support sustained increases in firing under steady light exposure.

Because stimuli at the two wavelengths were cone isoluminant, subtracting $655 \mathrm{~nm}$ from $460 \mathrm{~nm}$ responses helps reveal the component of the $460 \mathrm{~nm}$ response that is not attributable to 


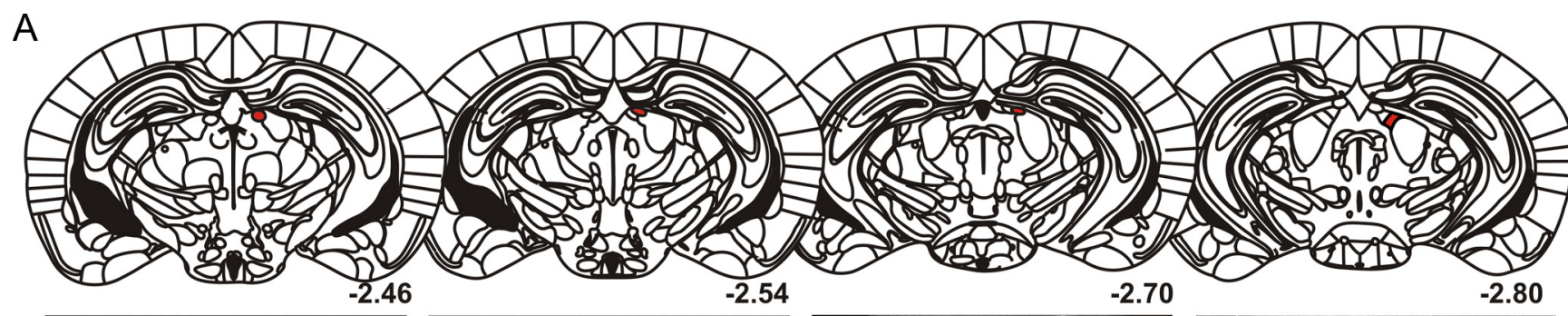

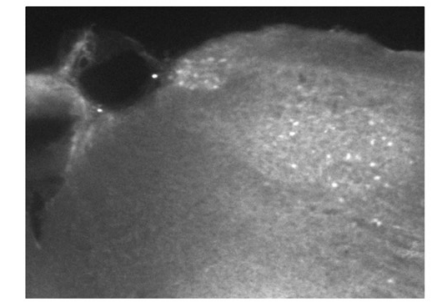

B

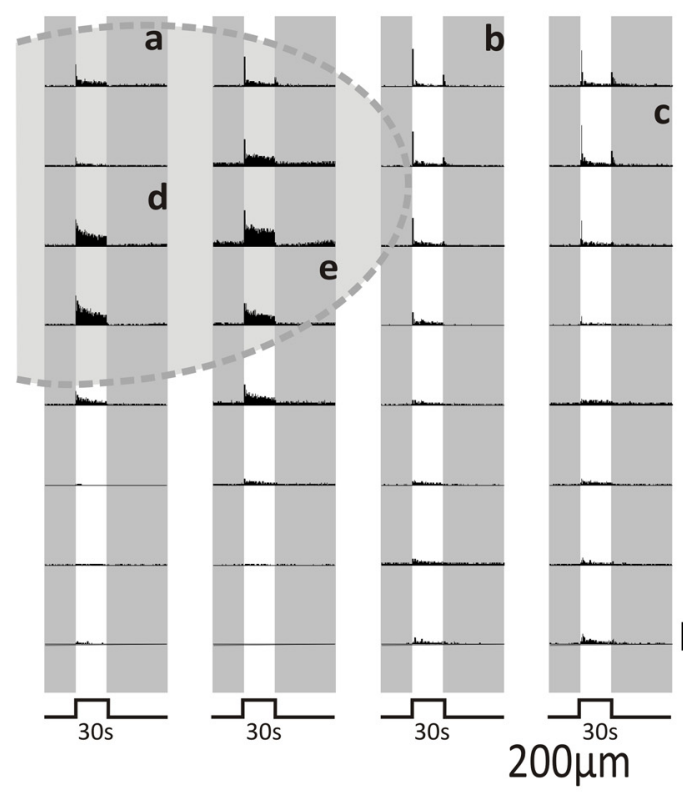

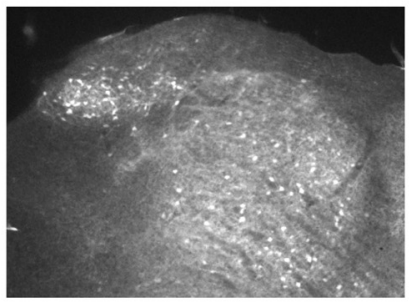

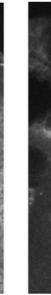

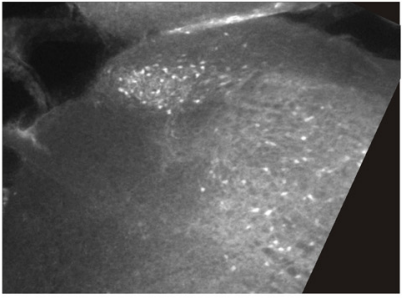

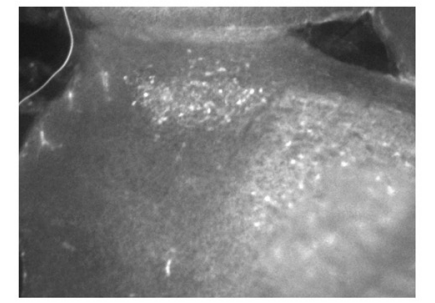

C

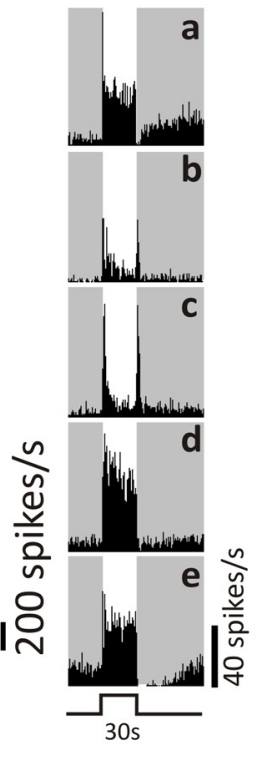

sustained $\bullet$ transient $\mathbf{O}$ unresponsive

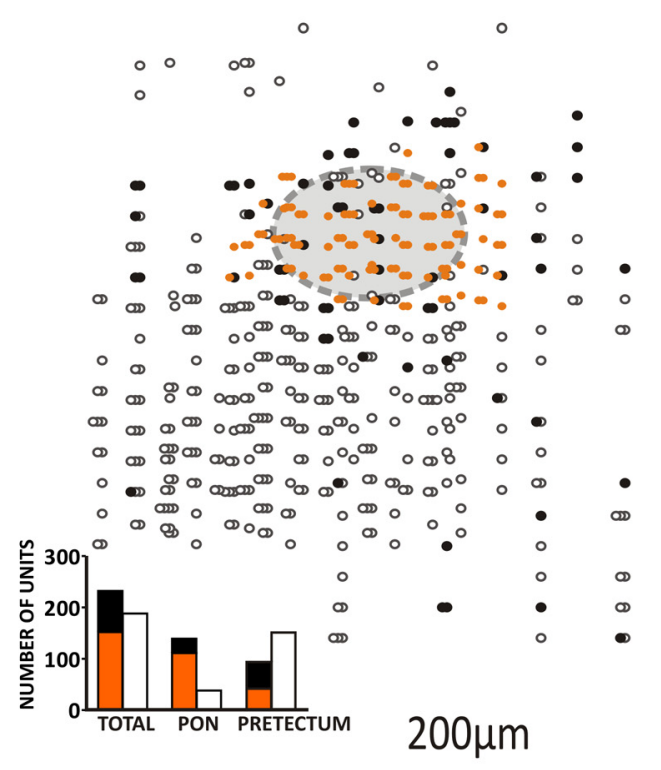

Figure 2. Light responses in the murine PON and surrounding pretectum. A, Location of the murine PON determined by parvalbumin (PV) immunohistochemistry (white staining). PV expression (bottom) is broadly consistent with the atlas definition of the PON (top), which shows the PON, highlighted in red, to extend from approximately -2.4 to $2.8 \mathrm{~mm}$ from bregma (Paxinos and Franklin, 2001). B, Representative multiunit responses to a $2 \mathrm{~s}, 460 \mathrm{~nm}$ stimulus $\left(15.8 \log _{10}\right.$ photons $\left./ \mathrm{cm}^{2} / \mathrm{s}\right)$. Each peristimulus time histogram corresponds to a single recording site, with timing of the light pulse shown in diagram form below and as a gap in the background shading. The shaded oval area in top right shows the approximate extent of the PON. Right panel shows representative single units extracted from recording sites within $(\boldsymbol{a}, \boldsymbol{d}, \boldsymbol{e})$ and outside $(\boldsymbol{b}, \boldsymbol{c})$ the PON. Most light-responsive neurons in the pretectum showed strong on excitation, but the degree to which this was sustained throughout light exposure was much greater in the PON. The anatomical distribution of such sustained (orange) and transient (black) cells as well as of those that were unresponsive to light (white) over a number of such recordings in Opn1mw mice is shown in C. Inset quantifies total numbers of each cell type. Total cells recorded from six animals: $n=420$. Within PON, $n=149$ sustained cells and $n=15$ transient cells.

long-wavelength-responsive cones. This manipulation highlights a tonic response component, elicited exclusively by shorter wavelengths, whose amplitude is retained throughout $30 \mathrm{~s}$ (Fig. 3C). According to current understanding, this tonic component should originate with melanopsin, and, indeed, irradiancedependent increases in sustained firing occurred over the known sensitivity range for melanopsin (Fig. 3B) (Lucas et al., 2001). Nonetheless, we tested this prediction using mice lacking either rods + cones $(r d / r d c l)$ or melanopsin $\left(O p n 4^{-1-}\right)$. The fundamental response properties of each genotype are summarized in Table 1. If melanopsin were the origin of the tonic increase in firing, then this aspect of the PON response should be retained in the former genotype but absent in the latter. We found that, in response to a $30 \mathrm{~s}, 460 \mathrm{~nm}$ pulse, $\mathrm{rd} / \mathrm{rd} \mathrm{cl}$ mice do indeed retain tonic compo- nents of the PON light response but clearly lack the phasic response seen in Opn1mw $w^{R}$ mice (Fig. 4A,B). Surprisingly, however, $O p n 4^{-1-}$ mice retained not only phasic but also tonic response components (Fig. $4 A, B$ ). This latter observation reveals that tonic activation of the PON is not entirely reliant on melanopsin. In fact, the magnitude of sustained firing was reduced in

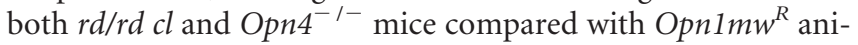
mals, raising the possibility that, in visually intact mice, both inner (melanopsin) and outer (rod/cone) retinal photoreceptors contribute to this response component.

Short-wavelength-sensitive cones support tonic responses Given the evidence that rods make little contribution to the PON response under these conditions, the tonic response detected in 


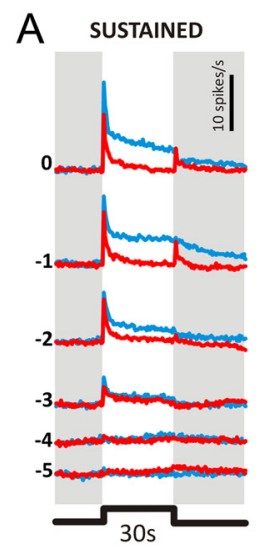

B 20-30s after lights on C
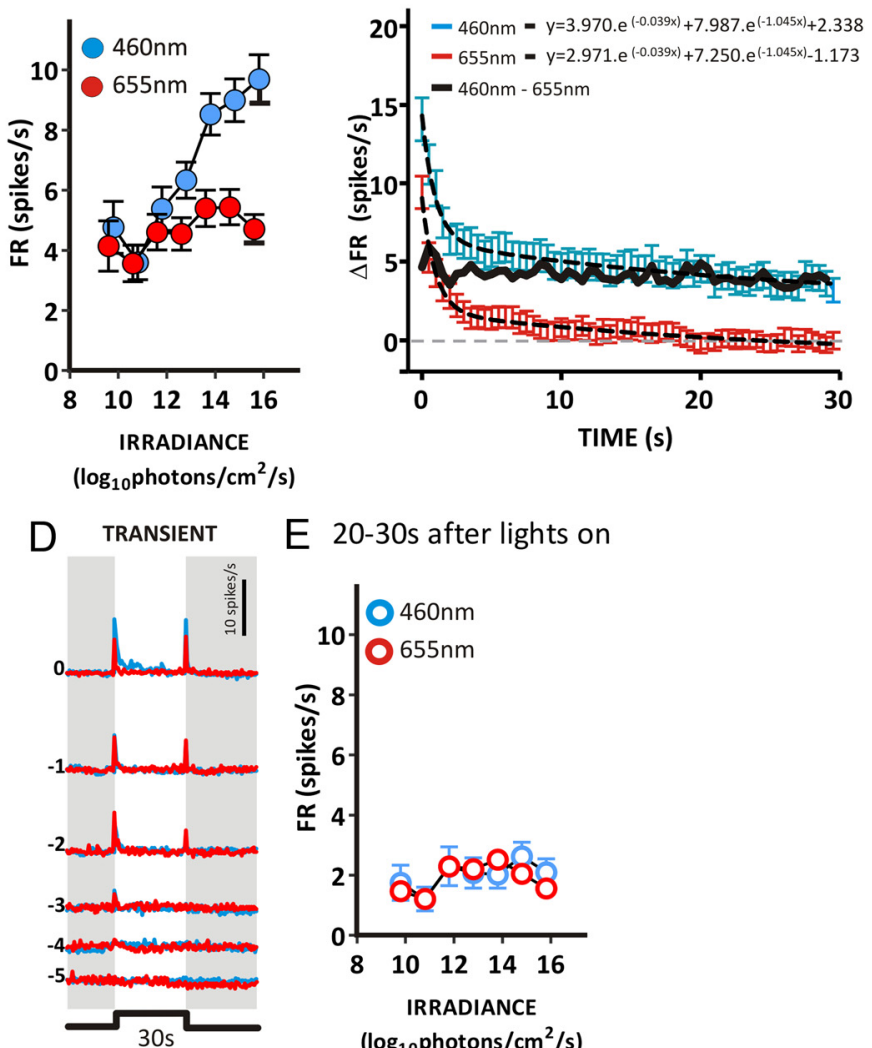

E 20-30s after lights on

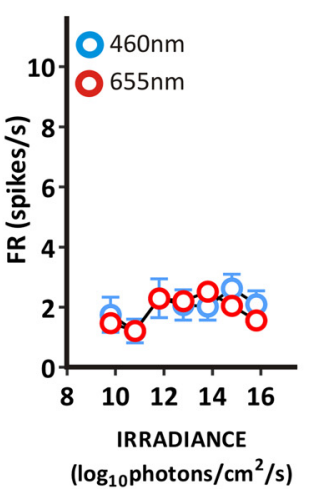

Figure 3. Spectral sensitivity of PON responses in $0 p n 1 m w^{R}$ mice. $A$, The mean response of PON cells with a sustained phenotype to $30 \mathrm{~s}$ LWS-isoluminant 460 and $655 \mathrm{~nm}$ (blue and red lines, respectively) stimuli. Four presentations of each stimulus were separated by a 300 s interstimulus interval. Numbers to the left depict irradiance as a $\log _{10}$ proportion of the brightest pulse (14.8 and $15.6 \log _{10}$ photons $/ \mathrm{cm}^{2} / \mathrm{s}$ for 460 and $655 \mathrm{~nm}$ stimuli, or $14.2 \log _{10} \mathrm{LWS}$-effective photons $/ \mathrm{cm}^{2} /$ s). The difference in sustained firing elicited by these two wavelengths is highlighted in $\boldsymbol{B}$, which shows the mean \pm SEM firing rate $20-30 \mathrm{~s}$ after stimulus onset as a function of irradiance. $C$, The decay of 460 and $655 \mathrm{~nm}$ responses in sustained cells, isoluminant for LWS opsin-effective photons $\left(14.2 \log _{10}\right.$ photons $\left./ \mathrm{cm}^{2} / \mathrm{s}\right)$. Both curves are fitted with two-phase exponential decay curves (dotted lines), with equations displayed in the inset. Responses to 460 and $655 \mathrm{~nm}$ show decay kinetics that are not significantly different ( $F$ test, $p=0.096$ ); this is confirmed by the subtraction of $655 \mathrm{~nm}$ responses from $460 \mathrm{~nm}$ (solid black line), revealing a steady-state elevation in firing rate that separates the two responses. $\boldsymbol{D}$ and $\boldsymbol{E}$ show equivalent data to $\boldsymbol{A}$ and $\boldsymbol{B}$ for the small number of transient neurons found in the $0 p n 1 \mathrm{mw} w^{R}$ PON. $n=151$ sustained and $n=15$ transient units from 6 mice.

Table 1. Response properties of $O p n 1 m w^{R}, O p n 4^{-/-}$, and $r d / r d$ cl mice

\begin{tabular}{|c|c|c|c|c|}
\hline & \multicolumn{2}{|l|}{ Opn1mw $w^{R}$} & \multirow{2}{*}{$\begin{array}{l}0 p n 4^{-1-} \\
460 \mathrm{~nm}\end{array}$} & \multirow{2}{*}{$\begin{array}{l}r d / r d c l \\
460 \mathrm{~nm}\end{array}$} \\
\hline & $460 \mathrm{~nm}$ & $655 \mathrm{~nm}$ & & \\
\hline Baseline FR & $4.56 \pm 0.21$ & $4.42 \pm 0.22$ & $3.33 \pm 0.86$ & $3.71 \pm 0.28$ \\
\hline Peak FR & $22.52 \pm 1.31$ & $15.58 \pm 0.99$ & $20.48 \pm 1.82$ & $11.08 \pm 1.78$ \\
\hline Sustained FR & $8.99 \pm 0.81$ & $4.71 \pm 0.48$ & $5.78 \pm 0.90$ & $7.12 \pm 0.90$ \\
\hline Sustained $\Delta F R$ & $4.65 \pm 0.62$ & $0.03 \pm 0.22$ & $2.22 \pm 0.43$ & $3.03 \pm 0.65$ \\
\hline Response latency (s) & $0.17 \pm 0.01$ & $0.21 \pm 0.02$ & $0.23 \pm 0.03$ & $7.82 \pm 1.16$ \\
\hline Off latency (s) & $1.30 \pm 0.15$ & $\mathrm{~N} / \mathrm{A}$ & $2.33 \pm 0.65$ & $12.97 \pm 1.91$ \\
\hline
\end{tabular}

Data reflect elements of the response of sustained units in the PON to 30 s pulses of 460 or $655 \mathrm{~nm}$ light at 14.8 or 15.6 $\log _{10}$ photons $/ \mathrm{cm}^{2} / \mathrm{s}$, respectively (note that these stimuli are calculated to be isoluminant for LWS opsin in Opn1mw $w^{R}$. All firing rates (FR) are expressed as spikes per second. Baseline FR was defined as the mean firing rate over the $20 \mathrm{~s}$ before stimulus presentation; peak FR as the maximum rate achieved during the $30 \mathrm{~s}$ light pulse (bin size, $50 \mathrm{~ms}$ ) and the sustained FR as the mean over the last $10 \mathrm{~s}$ of the 30 s stimulus. Sustained activity is also reported in terms of a change in $F R$ (sustained $\Delta F R$ ) calculated by subtracting baseline FR from sustained FR. Response latency was defined as time-to-peak FR after stimulus onset and off latency as the time taken for the sustained FR to fall $90 \%$ toward baseline after stimulus termination. All genotypes showed clear responses to steps of $460 \mathrm{~nm}$ light. Neither $0 p n 4^{-1-}$ or $\mathrm{rd} / \mathrm{rd} d$ mice responded to $655 \mathrm{~nm}$ (data not shown). $0 \mathrm{pn} 1 \mathrm{mw} \mathrm{w}^{R}$ animals did respond to $655 \mathrm{~nm}$, but this response lacked a sustained component, precluding calculation of "off latency" for this condition. Data show mean \pm SEM. Opn $1 m w^{R}, n=151$ sustained cells from 6 animals; $0 p n 4^{-1-}, n=68$ sustained cells from 6 animals; $r d / r d c l, n=63$ sustained cells from 8 animals.
$O p n 4^{-1-}$ mice presumably originates with cones. How then to explain the lack of tonic firing of Opn1mw ${ }^{R}$ mice exposed to coneactivating $655 \mathrm{~nm}$ light? One possibility is that it reflects compensatory rewiring after melanopsin loss. Alternatively, a cone population insensitive to the long-wavelength stimuli may support tonic responses. Although the vast majority of mouse cones would be expected to express the LWS cone opsin in Opn1mw $w^{R}$ mice and thus be responsive to $655 \mathrm{~nm}$ (Smallwood et al., 2003; Jacobs et al., 2007), a small number of so-called primordial S-cones express only SWS opsin $\left(\lambda_{\max }=365 \mathrm{~nm}\right.$; Haverkamp et al., 2005) and thus would be sensitive only to shorter wavelengths.

To determine whether the difference between cone contributions to PON activation as revealed by $655 \mathrm{~nm}$ in Opn $1 m w^{R}$ versus shorter-wavelength stimuli in Opn $4^{-1-}$ animals could be explained by a distinct contribution of Scones, we compared Opn $4^{-1-}$ responses to 460 and $600 \mathrm{~nm}$ stimuli isoluminant for MWS opsin (Fig. 4C). We found that, just as in Opn1m $w^{R}$ mice, the wavelength predicted to activate MWS-expressing cones $(600 \mathrm{~nm})$ did not sustain tonic firing, supporting the conclusion that this cone population does not drive strong tonic responses. Conversely, the shorterwavelength evoked sustained firing at intensities $>13 \log _{10}$ photons $/ \mathrm{cm}^{2} / \mathrm{s}$ (Fig. 4C). This corresponds to a threshold of $\sim 10 \log _{10}$ SWS opsin-effective photons/ $\mathrm{cm}^{2} / \mathrm{s}$ (see Materials and Methods), significantly lower than described for shortwavelength pupil responses in mice (Yao et al., 2006) but consistent with other descriptions of cone-based vision (Nathan et al., 2006; Lall et al., 2010).
An S-cone-dependent off inhibition

The tonic response of Opn $4^{-1-}$ to high levels of $460 \mathrm{~nm}$ light indicates a distinct contribution of S-cones to PON activation. Closer examination of response waveforms suggests an additional influence of this receptor class. Light responses in $\mathrm{rd} / \mathrm{rd} \mathrm{cl}$ mice persisted for many seconds after stimulus termination (Fig. $4 D$, panel 1), consistent with the reported slow decay in the melanopsin photoresponse (Berson et al., 2002). In contrast, when stimulated with melanopsin-silent $655 \mathrm{~nm}$ light, the Opn1mw ${ }^{R}$ PON showed a transient OFF excitation (Fig. $4 D$, panel 2). Neither of these patterns of poststimulus firing was simply recapitulated in the response of Opn1mw ${ }^{R}$ to $460 \mathrm{~nm}$ light (Fig. $4 D$, panel 3 ). After moderate irradiance pulses $\left(\leq 13 \log _{10}\right.$ photons $/ \mathrm{cm}^{2} / \mathrm{s}$ ) at this wavelength, these mice showed a gradual decline in firing, presumably reflecting either melanopsin persistence and/or cone-derived off excitation. However, at higher irradiances, light offset was accompanied by a rapid and complete cessation of light-evoked firing. A similar effect was never observed at $655 \mathrm{~nm}$ in this genotype (Fig. $4 D$, panel 2). This 
short-wavelength-specific event was not reliant on melanopsin, because similar off-inhibitory responses were observed in Opn $4^{-1-}$ mice under high irradiance 460 $\mathrm{nm}$ but not $600 \mathrm{~nm}$ stimuli (Fig. $4 D$, panels 4 and 5). It seems likely then that this sustained off-inhibition response also arises from S-cones.

Responses to contrast versus irradiance The evidence that S-cones support sustained firing in response to light steps from darkness is inconsistent with the simple view that melanopsin is required to support such tonic photoactivation. What then is the unique contribution of melanopsin to the PON light response, if any? We set out to address this question using more "natural" modulations in illuminance. Light steps from darkness present a strong signal for systems tracking changes in either absolute or relative light intensity (termed here "irradiance" and "contrast" information, respectively). To distinguish between these two fundamentally different qualities of visual information, we presented a steady $460 \mathrm{~nm}$ background illumination at either 12.2 or $13.2 \log _{10}$ MWS opsin-effective photons $/ \mathrm{cm}^{2} / \mathrm{s}$ and recorded responses to a 2 s step of 10 -fold higher effective illuminance (Fig. 5). In this protocol, the change in relative illuminance during the light step (contrast) was equivalent under each background (10-fold increase), whereas irradiance of the step was either 13.2 or $14.2 \log _{10}$ MWS opsin-effective photons $/ \mathrm{cm}^{2} / \mathrm{s}$ depending on the background. Opn1mw ${ }^{R}$ mice showed large changes in firing rate to the step (relative to baseline firing rate), whether it was rendered in cone-isolating $(655 \mathrm{~nm})$ or melanopsin-stimulating (460 nm) wavelengths. The higher-illuminance $460 \mathrm{~nm}$ step drove significantly larger responses than the lower-illuminance step, confirming the ability of PON to encode irradiance. However, there was no equivalent increase in the response to the higher-illuminance $655 \mathrm{~nm}$ step. Under these conditions then, PON activity can encode the difference in irradiance between steps presented against the two backgrounds but only when stimuli target receptors other than MWS-expressing cones.

To determine whether this irradiance coding ability relies on S-cones and/or melanopsin, we repeated these experiments in Opn $4^{-1-}$ mice (Fig. 5). In this genotype, there was no increase in the magnitude of responses when presented against the higher background illumination to steps rendered in either S-cone silent $(600 \mathrm{~nm})$ or activating $(460 \mathrm{~nm})$ wavelengths. These data then indicate that, in the absence of melanopsin, the mouse PON responds well to a change in light intensity (temporal contrast) but has an impaired ability to encode absolute irradiance.

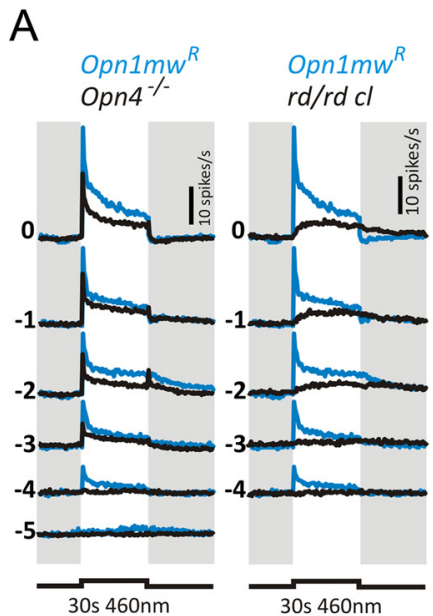

B
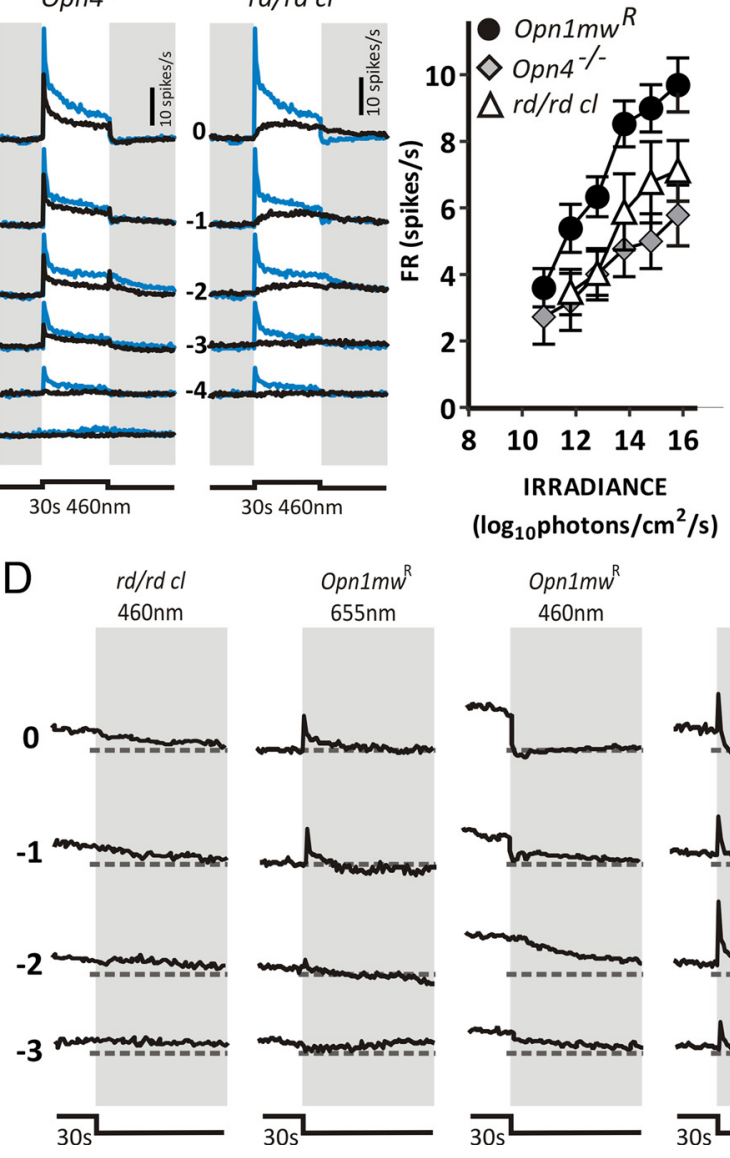

C

$460 \mathrm{~nm}$

$600 \mathrm{~nm}$

$460 n m-600 n m$
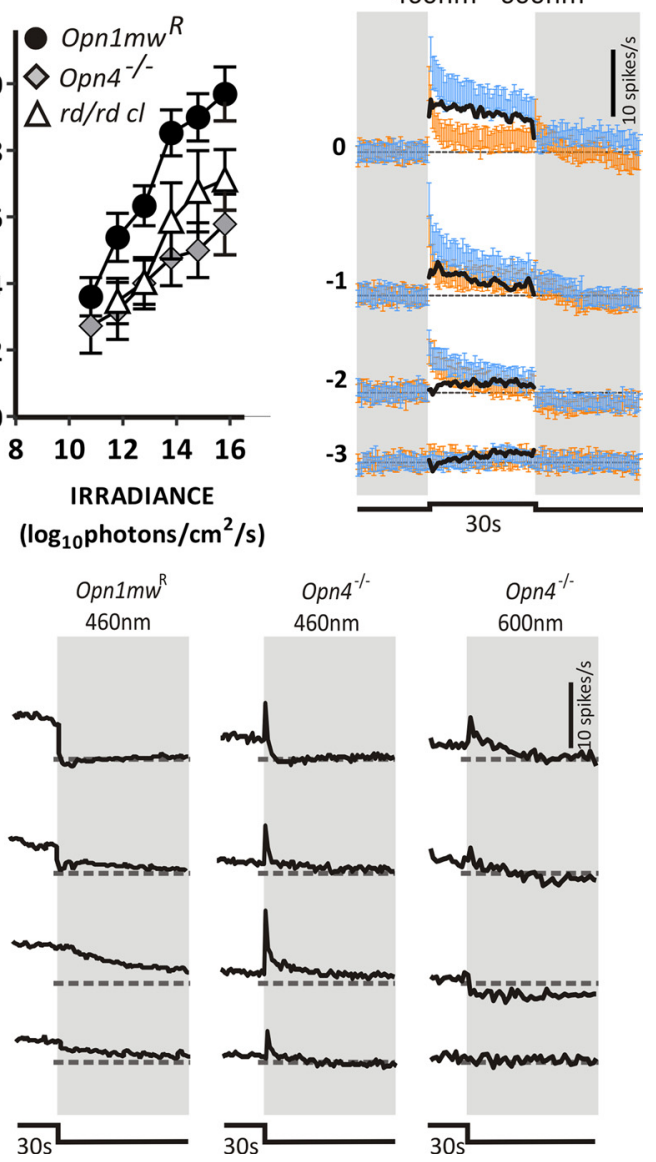

Figure 4. A unique S-cone contribution to the PON response. A, Mean responses of sustained cells in Opn $4^{-1-}$ or $\mathrm{rd} / \mathrm{rd} \mathrm{cl}$ (black lines) and $0 p n 1 \mathrm{mw}^{R}$ (blue lines) mice exposed to $30 \mathrm{~s}, 460 \mathrm{~nm}$ stimuli over a range of irradiances. Four presentations of each stimulus were separated by a 300 s interstimulus interval. Number to left of each trace indicates irradiance as a $\log _{10}$ proportion of the brightest pulse $\left(15.8 \log _{10}\right.$ photons $\left./ \mathrm{cm}^{2} / \mathrm{s}\right) . \boldsymbol{B}$, A plot of mean \pm SEM firing rate $20-30 \mathrm{~s}$ after stimulus onset as a function of irradiance confirms the ability of all genotypes to show sustained firing at higher irradiances. $C$, Mean \pm SEM firing rate above confirm the existence of a short-wavelength-sensitive sustained component to the PON response in this genotype. Numbers to left of traces depict irradiance as a $\log _{10}$ proportion of the brightest stimulus $\left(14.2 \log _{10}\right.$ MWS opsin-effective photons $\left./ \mathrm{cm}^{2} / \mathrm{s}\right)$. $600 \mathrm{~nm}$ from $460 \mathrm{~nm}$ responses (solid black line) reveals a short-wavelength-specific response component at higher irradiances that shows little decay over $30 \mathrm{~s}$ of light exposure. $\boldsymbol{D}$, Mean firing rate above prestimulus baseline for sustained cells in the PON around the end of a $30 \mathrm{~s}$ pulse. Left to right, $r d / \mathrm{rd} \mathrm{cl} 460 \mathrm{~nm}, 0 p n 1 m w^{R} 655 \mathrm{~nm}, 0 p n 1 \mathrm{mw}^{R} 460 \mathrm{~nm}, 0 \mathrm{pn} 4^{-1-} 460 \mathrm{~nm}$, and $600 \mathrm{~nm}$ responses. Numbers to left depict $\log _{10}$ irradiance relative to brightest stimuli $\left(15.8,15.3\right.$, and $15.6 \log _{10}$ photons $/ \mathrm{cm}^{2} / \mathrm{s}$ for 460,600 , and $655 \mathrm{~nm}$, respectively). Recordings at each irradiance across all genotypes and wavelengths were isoluminant for MWS or, in the case of Opn $1 \mathrm{mw}^{R}$ mice, LWS opsin. Dashed line represents baseline firing rate. Note the strong inhibition at lights off in the conditions expected also to activate $S$-cones $\left(460 \mathrm{~nm}\right.$ irradiances above -2 in $0 p n 1 \mathrm{mw}^{R}$ and $0 p n 4^{-1-}$ mice). $0 p n 1 m w^{R}, n=151$ sustained cells from 6 animals; $0 p n 4^{-\prime-}, n=68$ sustained cells from 6 animals; $r d / r d c l$, $n=63$ sustained cells from 8 animals.

\section{S-cones extend the temporal frequency tuning of the mouse PON}

We next asked how melanopsin and the two cone populations combine to track gradual changes in light intensity. To this end, we first set out to describe temporal frequency tuning characteristics for PON neurons in Opn1mw $w^{R}$ and Opn $4^{-1-}$ mice using sinusoidal modulations (Fig. $6 A, B$ ). We found that, when rendered in $460 \mathrm{~nm}$ light, both genotypes were able to follow oscillations over a wide range of frequencies $(0.01-25 \mathrm{~Hz})$. Responses to higher-frequency oscillations $>5 \mathrm{~Hz}$ were typically complex (data not shown). However, at lower frequencies $(<5 \mathrm{~Hz})$, sinusoidal modulations drove high-amplitude, in-phase oscillations in PON firing. There was no consistent difference between geno- 

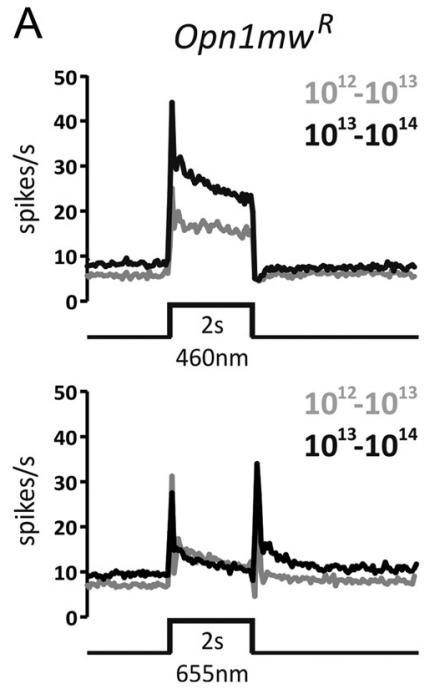
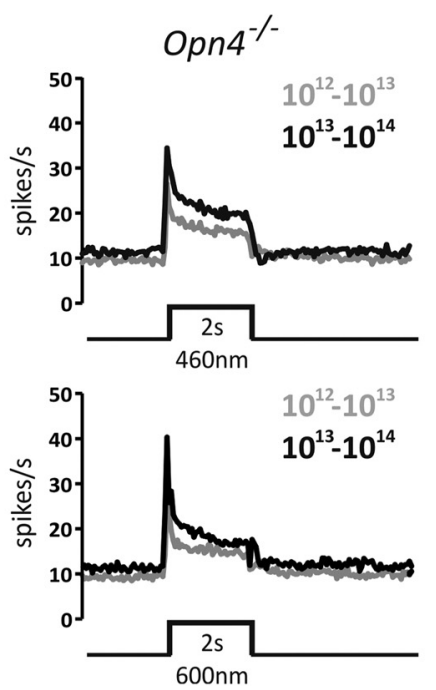

B Opn $1 m w^{R}$ FR $0-2 s$

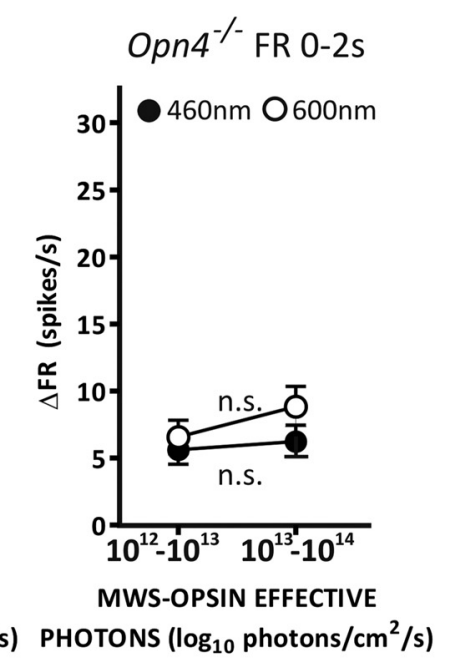

Figure 5. Responses of $0 p n 1 m w^{R}$ and $0 p n 4^{-1-}$ mice to irradiance and contrast. $A$, Mean firing rate in sustained neurons in the PON of $0 p n 1 m w^{R}$ or $0 p n 4^{-1-}$ mice exposed to a $2 \mathrm{~s}, 1-\log$ unit, step in irradiance. The numbers in the top right of each trace show the irradiance in MWS-effective (for Opn4 ${ }^{-1-}$ ) or LWS-effective (for Opn $1 \mathrm{mw} w^{R}$ ) photons $/ \mathrm{cm}^{2} / \mathrm{s} \mathrm{of} \mathrm{the} 460 \mathrm{~nm}$ background $($ panel 1) and the $2 \mathrm{~s} \mathrm{step} \mathrm{(panel} \mathrm{2).} \mathrm{In} \mathrm{the} \mathrm{top} \mathrm{two} \mathrm{panels,} \mathrm{the} \mathrm{step} \mathrm{was} \mathrm{rendered} \mathrm{in} 460 \mathrm{~nm}$. In the bottom two, the step was rendered in a melanopsin and S-cone silent wavelength, $655 \mathrm{~nm}$ for $0 p n 1 \mathrm{mw}{ }^{R}$ and $600 \mathrm{~nm}$ for $\mathrm{Opn}^{-I-}$. A strong response to the light step was observed in all conditions. $\boldsymbol{B}$, To determine the degree to which these were responses to contrast versus stimulus irradiance, the average change in firing rate (FR) from baseline during stimulus presentation was compared between high- and low-irradiance steps for each wavelength, in each genotype (symbols show mean \pm SEM for all animals). The higher-irradiance step only drove a significantly larger response when it was rendered in $460 \mathrm{~nm}$ and presented to $0 p n 1 w^{R}$ mice (one-tailed $t$ test, ${ }^{* *} p>0.01$ ). This is the only situation in which melanopsin is predicted to contribute to the responses. In all other conditions, there was no increase in the magnitude of responses when presented against the higher background illumination, suggesting that responses were defined mostly by the relative increase in irradiance (contrast), which was constant across conditions. Opn $1 \mathrm{mw} w^{R}, n=52$ sustained cells from 6 animals; $0 p n 4^{-1-}, n=48$ sustained cells from 7 animals.

types, indicating that melanopsin was not required to support this behavior. Consistent with this view, the strong positive correlation between frequency and response amplitude indicates that, under these conditions, the critical determinant of the PON response was not the absolute difference in irradiance (which remained constant) but rather the rate of change.

As additional confirmation that melanopsin is not required to track oscillations in illuminance over this range of frequencies, we recorded pupil size in awake mice exposed to sinusoidal stimuli (Fig. 6C-F). Consistent with our recordings in the PON, both $O p n 1 m w^{R}$ and Opn4 ${ }^{-1-}$ mice were able to track sinusoidal changes in illumination at least over the $0.05-1 \mathrm{~Hz}$ frequency range. The impact of losing melanopsin was apparent in the substantial increase in average pupil size in $O p n 4^{-1-}$ mice, as reported previously for steady illumination (Fig. 6 F) (Lucas et al., 2003). However, the sinusoids drove similar amplitude oscillations in pupil size in the two genotypes (Fig. 6E), confirming that the pupillomotor system does not rely on melanopsin for tracking such relatively gradual changes in illumination.

It seems, then, that cones define the pupil response to even fairly gradual changes in illumination. Interestingly, however, this effect was wavelength dependent in both $O p n 1 m w^{R}$ and Opn $4^{-1-}$ mice (Fig. 7A). In each genotype, a majority of lightresponsive cells had significant responses to the lowest-frequency oscillation tested $(0.01 \mathrm{~Hz})$ at $460 \mathrm{~nm}$. Those with the highest response amplitude at this wavelength also showed significant oscillations in firing to the $0.01 \mathrm{~Hz}$ longer-wavelength stimuli, albeit of much reduced amplitude. In contrast, many cells only showed significant responses to $600 / 655 \mathrm{~nm}$ sinusoids at higher frequencies (Fig. $7 \mathrm{~B}, C$ ). As a result, the ability of both $O p n 1 m w^{R}$ and $O p n 4^{-1-}$ PON cells to track gradual changes in illumination was superior when rendered in shorter-wavelength light. This high-amplitude response to slow oscillations at short wavelengths matched the predicted sensitivity of S-cones in Opn $4^{-1-}$ mice, being observed at an SWS opsin-effective irradiance $>9$ $\log _{10}$ photons $/ \mathrm{cm}^{2} / \mathrm{s}$ at $460 \mathrm{~nm}$ but not to $600 \mathrm{~nm}$ stimuli at any irradiance tested (Fig. $7 D, E)$.

\section{Discussion}

In Opn $1 m w^{R}$ and Opn $4^{-1-}$ mice, we find that even the brightest $600 / 650 \mathrm{~nm}$ stimuli evoke only a limited array of electrophysiological responses in the mouse PON. Thus, $30 \mathrm{~s}$ pulses rendered in these long wavelengths elicit only transient increases in firing at lights on (and sometimes off) that decay to baseline within a few seconds of continuous exposure. Similarly, sinusoidal modulations at 600/650 $\mathrm{nm}$ drive high-amplitude changes in firing only when presented at high temporal frequencies. Finally, the PON seems able to encode the relative but not absolute irradiance of $600 / 655 \mathrm{~nm}$ steps in illuminance.

These $600 / 650 \mathrm{~nm}$ stimuli lie outside of the sensitivity range of mouse SWS opsin but should nonetheless impact almost all cones in this species. The current view is that $>95 \%$ of mouse cones coexpress MWS and SWS opsins (Szél et al., 1992; Röhlich et al., 1994; Lyubarsky et al., 1999; Nikonov et al., 2006). The relative expression of the two pigments follows a dorsoventral gradient and can favor SWS opsin by as much as 3000:1 in the ventral retina (Nikonov et al., 2005). However, we estimate that even the most "SWS-biased" of these cones should be at most $10 \times$ less sensitive to the longer wavelengths $(600 / 655 \mathrm{~nm})$ than $460 \mathrm{~nm}$ (see Materials and Methods). It seems, therefore, that the brighter $600 / 650 \mathrm{~nm}$ stimuli would strongly activate $>95 \%$ of the cone population. On this basis, the limited ability of such stimuli to support sustained activation or responses to low-frequency oscillations suggests that these photoreceptors provide the mouse pupillomotor system primarily with information about relatively abrupt changes in light intensity. This conclusion is in accord with our recent electrophysiological characterization of responses driven by MWS-expressing cones in the mouse suprachi- 
asmatic nuclei (SCN; site of the master circadian clock; Brown et al., 2011) and with behavioral and electrophysiological evidence that cones have a relatively proscribed influence on NIF functions (DkhissiBenyahya et al., 2007; Brown et al., 2010; Dollet et al., 2010; Lall et al., 2010; McDougal and Gamlin, 2010).

The $460 \mathrm{~nm}$ stimuli elicited a much wider array of responses. These included (1) tonic increases in firing persisting over at least $30 \mathrm{~s}$ of continuous light exposure, (2) a strong off inhibition, and (3) highamplitude changes in firing in response to even low-frequency oscillations in light intensity. The retention of these response characteristics in Opn $4^{-1-}$ mice, at least to some degree, implies the involvement of a shorter-wavelength-sensitive photoreceptor other than melanopsin. In theory, mouse rods $\left(\lambda_{\max }=498 \mathrm{~nm}\right)$ could perform this function. However, two lines of evidence argue against this explanation. First, PON responses were elicited only by relatively bright $460 \mathrm{~nm}$ light (response threshold, $\sim 10 \quad \log _{10}$ photons $/ \mathrm{cm}^{2} / \mathrm{s}$ ), well above the predicted threshold for rod-based vision (Sampath et al., 2005; Nathan et al., 2006; Lall et al., 2010; Naarendorp et al., 2010). Second, their spectral sensitivity does not match that of rods. Mouse rods are only $\sim 30 \times$ less sensitive to 600 than $460 \mathrm{~nm}$ light. These two wavelengths should therefore drive an equivalent rod response when the longer is $\sim 30 \times$ brighter. In fact, we did not observe significant sustained firing, off inhibition, or strong responses to low-frequency oscillations to even the brightest $600 \mathrm{~nm}$ stimuli (which were at least $100 \times$ the threshold for observing these events at $460 \mathrm{~nm}$ ).

The most parsimonious explanation of our data is therefore that a population of cone photoreceptors uniquely sensitive to shorter wavelengths makes a particular contribution to the PON light response. Haverkamp et al. (2005) have described such a population of cones in the mouse retina. Comprising 3-5\% of the total, these so-called primordial S-cones appear to express SWS but not MWS opsin. They evade the typical cone opsin expression gradients, being found in equal density across the retina, and have a unique morphology. A distinct primordial S-cone retinal circuitry has also been described. This comprises a dedicated class of $\mathrm{ON}$ bipolar cell (Haverkamp et al., 2005; Li and DeVries, 2006) that contact AII amacrine cells (Puller and Haverkamp, 2011), allowing $\mathrm{S}$-cones to drive on and off responses in retinal ganglion cells (Ekesten and Gouras, 2005). Until now, the significance of primordial S-cones for vision has been considered only in the context of color discrimination (Jacobs et al., 2007;

A

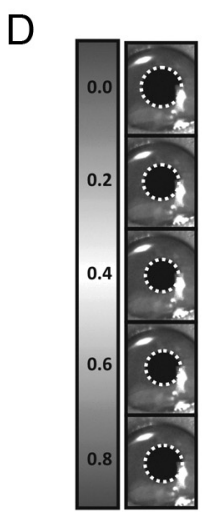

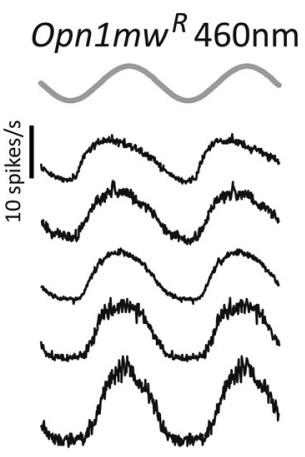
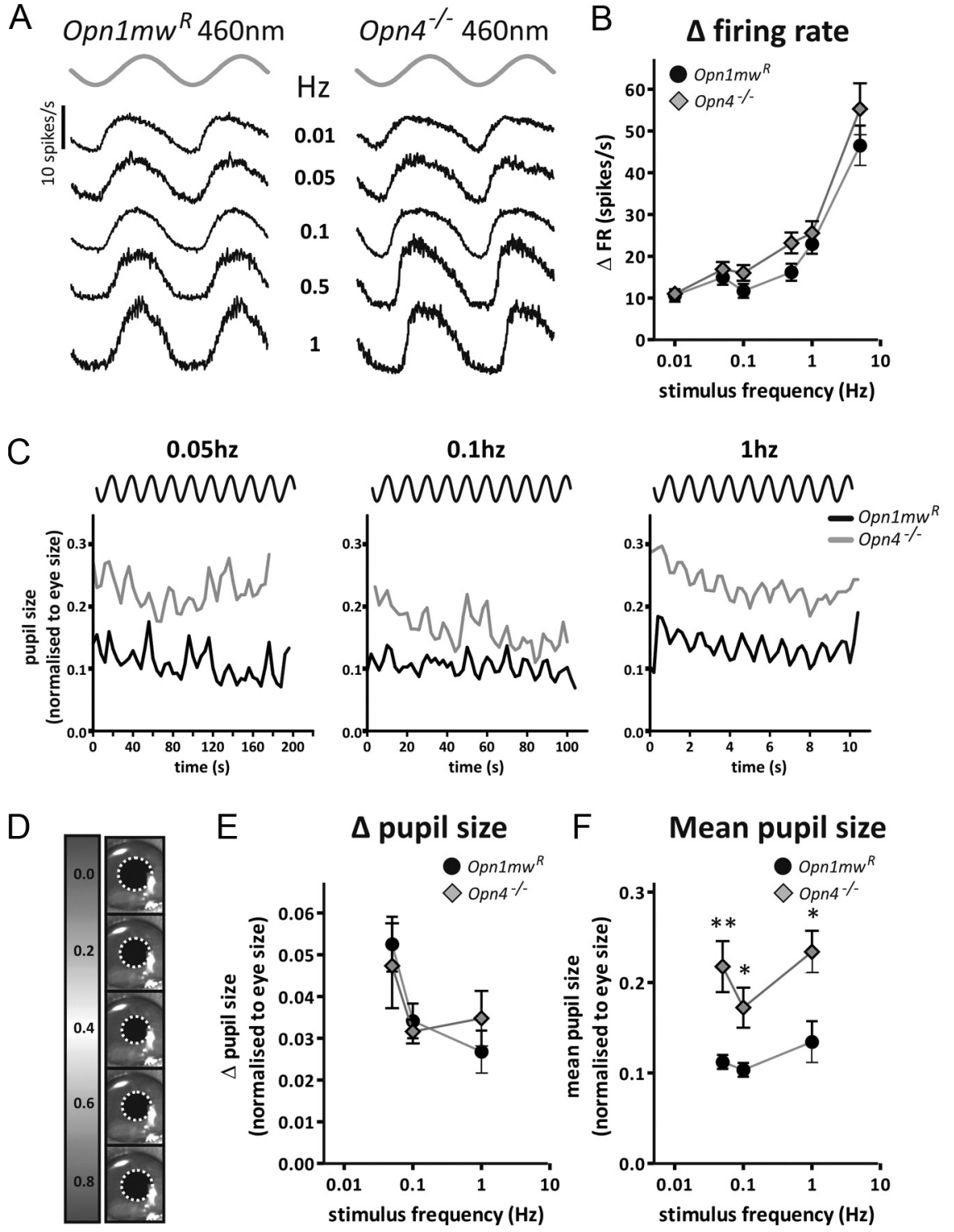

Figure 6. Responses of $O p n 1 m w^{R}$ and $O p n 4^{-1-}$ mice to sinusoidal oscillations in light intensity. A, Average change in firing rate (relative to baseline) of PON neurons in $0 \mathrm{pn} 1 \mathrm{mw}^{R}$ and $0 \mathrm{pn} 4^{-1-}$ mice to sinusoidal oscillations in light intensity (peak and trough irradiances 13.2 and 14.2 MWS opsin-effective photons $/ \mathrm{cm}^{2} / \mathrm{s}$, respectively). Responses to sinusoids in the $0.01-1 \mathrm{~Hz}$ range are shown with the stimulus depicted in gray above to give an idea of phasing. $\boldsymbol{B}$, The strong dependence of response amplitude on stimulus frequency and the lack of a marked deficit in the $O p n 4^{-1-}$ response was confirmed in mean \pm SEM peak-to-trough amplitudes. Only those units showing a statistically significant response at any frequency $\left(p<0.001, \chi^{2}\right.$ periodogram) are included here. $n=52$ cells from $60 \mathrm{pn} 1 \mathrm{mw} \mathrm{w}^{R}$ animals; $n=48$ cells from $70 \mathrm{pn} 4^{-1-}$ mice. C, Traces of pupil size for representative $0 p n 1 m w^{R}$ and $0 p n 4^{-1-}$ mice exposed to sinusoidal oscillations in light intensity (phasing of stimuli shown above each graph; peak and trough irradiances 12.3 and $13.3 \mathrm{MWS}$ opsin-effective photons $/ \mathrm{cm}^{2} / \mathrm{s}$, respectively) at $0.05,0.1$, and $1 \mathrm{~Hz}$ confirms the ability of both genotypes to respond over this frequency range. Modulations in pupil size were best fit with sinusoidal curves of the correct frequency compared with a straight line ( $F$ test, $p<0.05$ at all frequencies in $0 p n 1 m w^{R}$ and $0 p n 4^{-1-}$ mice). An idea of the absolute magnitude of these responses is provided in $\mathbf{D}$, showing pupil imaged for an $0 p n 1 m w^{R}$ mouse during one cycle of a $1 \mathrm{~Hz}$ sinusoid (figures to left show time in seconds after trough in irradiance). $\boldsymbol{E}$, The magnitude of the peak-to-trough oscillation in pupil size was not noticeably different between genotypes. $\boldsymbol{F}$, The overall degree of pupil constriction (mean pupil size across oscillations) was, however, significantly greater in $0 p n 1 \mathrm{mw}^{R}$ animals. Data are compared with two-tailed $t$ test, ${ }^{*} p>0.05$, ${ }^{* *} p>0.01$. Symbols show mean \pm SEM pupil size normalized to eye size; $n=5$ animals for each group.

Ekesten and Gouras, 2008; Puller and Haverkamp, 2011). However, our findings suggest that they also play a unique role in NIF processes. It will be interesting, therefore, to determine whether the primordial S-cone circuitry targets ipRGCs and the degree to which the sensory characteristics of this pathway match those of short-wavelength responses in the PON described here. 
A

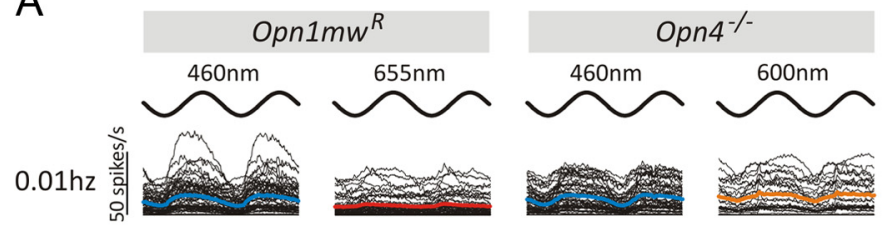

$0.05 \mathrm{hz}$ 商
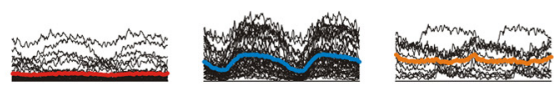

$0.1 \mathrm{hz}$
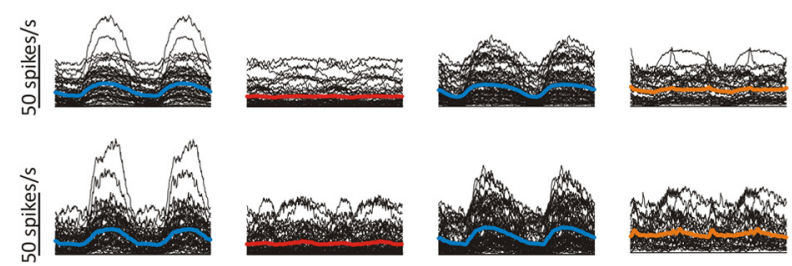

$1 \mathrm{hz}$
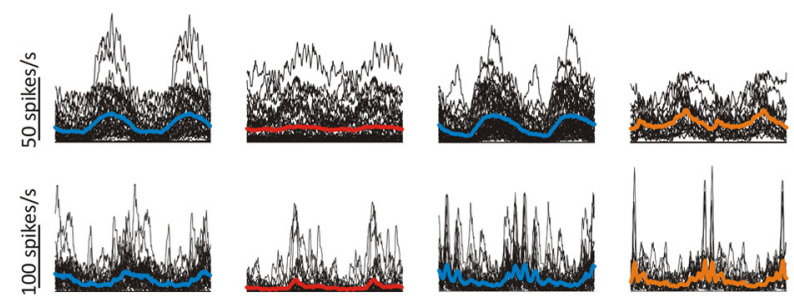

$5 \mathrm{hz}$

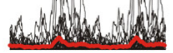
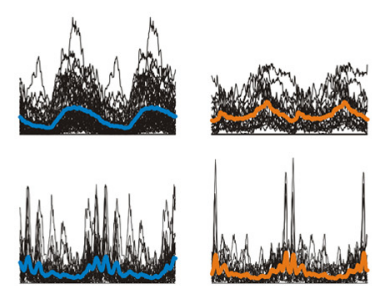

B

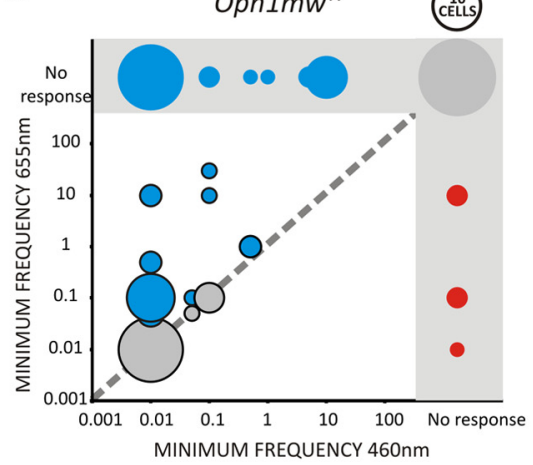

D

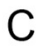

Opn $4^{-/}$
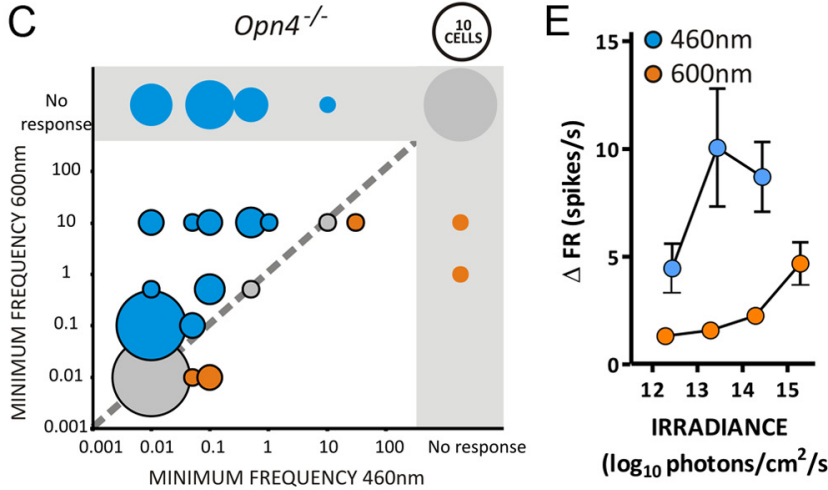

Figure 7. Wavelength-dependent temporal frequency tuning within the PON. A, Traces of the change in firing (with respect to baseline) elicited by sinusoidal modulations in light intensity over a range of frequencies rendered in either a short $(460 \mathrm{~nm})$ or longer $(655 / 600 \mathrm{~nm})$ wavelength for individual $0 \mathrm{pn} 1 \mathrm{mw} w^{R}$ and $0 \mathrm{pn} 4^{-1-}$ cells. The stimulus is shown above for phase information. Solid blue/red/orange lines depict the mean response for each condition. Only cells showing a significant change in firing rate ( $\chi^{2}$ periodogram, $\left.p<0.001\right)$ in that condition were included. Peak-totrough irradiance was set at 13.2 to $14.2 \mathrm{LWS} / \mathrm{MWS}$ opsin-effective photons $/ \mathrm{cm}^{2} / \mathrm{s}$ under all conditions. The enhanced ability to track low-frequency oscillations at $460 \mathrm{~nm}$ was also evident in plots $(\boldsymbol{B}, \boldsymbol{C})$ depicting the minimum frequency at which significant responses were observed at each wavelength in $0 \mathrm{pn} 1 \mathrm{mw} \mathrm{w}^{R}(\boldsymbol{B})$ and $0 \mathrm{pn} 4^{-1-}(\boldsymbol{C})$ mice. Circled area is scaled to represent number of cells in each group (circle size for 10 cells shown above each graph for comparison) and color coded such that blue represents cells showing a lower-threshold frequency at 460 than $655 / 600 \mathrm{~nm}$, $\mathrm{red} /$ orange cells for which the converse was true, and gray cells whose threshold frequency was the same at both wavelengths. Cells showing no significant response to either or both wavelengths are found in the gray shaded area of each graph. The spectral sensitivity of high-amplitude responses at lower frequencies was consistent with an $\mathrm{S}$-cone origin. Thus, plots of either average response profile $(\boldsymbol{D})$ or response amplitude ( $\boldsymbol{E}$; peak-to-trough change in firing) in $0 \mathrm{pn4^{-1- }}$ mice exposed to $0.1 \mathrm{~Hz}$ sinusoids of equivalent contrast (10X increase MWS-effective irradiance from trough-to-peak) revealed large responses at 460 but not $600 \mathrm{~nm}$ and only at higher mid-point irradiances (shown as figures reporting $\log _{10}$ proportion of the brightest condition in $\boldsymbol{D}$ and in total photon flux for $\boldsymbol{E}$ ). $n=52$ cells from $60 \mathrm{pn} 1 \mathrm{mw} \mathrm{w}^{R}$ and $n=48$ cells from $70 \mathrm{pn} 4^{-1-}$ animals.

The evidence presented here that S-cone pathways support tonic activation of the PON blurs the distinction between melanopsin and cone contributions to NIF vision. It remains to be determined whether S-cone-driven responses are sustained beyond the $30 \mathrm{~s}$ over which we recorded. If so, this would imply that S-cones provide some of the information about steady-state levels of illumination previously considered attributable to melanopsin. Nevertheless, the balance of our data is consistent with the view that the major determinant of the PON response to S-cone activation is the degree of temporal contrast. Thus, we did

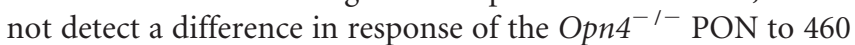
$\mathrm{nm}$ light steps of equivalent contrast (with respect to background illuminance) but divergent irradiance. Moreover, we observed a strong positive correlation between response amplitude and temporal frequency for sinusoidal oscillations at both 600/655 and $460 \mathrm{~nm}$. This latter observation indicates that the magnitude of the PON response under these conditions is determined primarily by the rate of change in light intensity rather than its absolute magnitude (which was kept constant).

In summary, then, our data are consistent with the view that cones are primarily responsible for encoding changes in relative light intensity (temporal contrast) for the PON. However, the difference in temporal frequency tuning characteristics of the PON at short and long wavelengths reveals that, although changes need to be relatively abrupt to elicit large responses via the majority MWS-expressing cones, S-cone pathways effectively track much slower changes. The inclusion of multiple cone pathways with different temporal frequency tuning characteristics then extends the sensory capabilities of the PON. The missing part of this picture is the temporal frequency tuning characteristics of melanopsin. We might expect this receptor to track stimulus irradiance regardless of the rate of change (i.e., to be refractory to temporal contrast), but this remains untested.

A final question is whether the unique contribution of S-cones to PON activity is a general feature of NIF vision. Few studies have explicitly addressed this possibility. Dacey et al. (2005) and Schmidt and Kofuji (2010) explored short-wavelength responses in primate and mouse ipRGCs, respectively. Although the former revealed a distinct S-cone off response component in the monkey, short and longer wavelengths elicited similar responses in the mouse. Importantly, however, in neither case were stimuli particularly suited to determine the unique S-cone characteristics revealed here. At the whole-animal level, it has been known for many years that short wavelength (UV) stimuli evoke highamplitude circadian phase shifts in rodents (Provencio and Foster, 1995). Because this appears not to be the case for stimuli targeting medium-wavelength-sensitive cones (Dkhissi-Benyahya et al., 2007; Lall et al., 2010), this may reflect a unique S-cone contribution to circadian entrainment. However, Syrian hamsters are also UV 
responsive (von Schantz et al., 1997) despite evidence that they lack SWS opsin (von Schantz et al., 1997; Calderone and Jacobs, 1999; GenBank accession number AH010729.1). One way of resolving this uncertainty regarding S-cone inputs to the circadian system would be to undertake a parallel series of experiments to those reported here but targeting recording electrodes to the SCN. We have recently compared responses to 655 and $460 \mathrm{~nm}$ in the SCN and surrounding hypothalamus of $O p n 1 m w^{R}$ mice (Brown et al., 2011) and found that, just as in the PON, only the shorter wavelength could support persistent firing in the hypothalamus. On that basis, we concluded that melanopsin dominates sustained responses in the $\mathrm{SCN}$, a conclusion supported by the reported effects of melanopsin knock-out (Mure et al., 2007). Nonetheless, it remains possible that a distinct S-cone contribution to SCN light responses would also become apparent with the use of brighter and/or shorter-wavelength stimuli. It will be important then to revisit this question using $\mathrm{Opn} 4^{-/-}$mice and/or more sophisticated techniques for isolating S-cone contributions to the composite response.

\section{References}

Altimus CM, Güler AD, Alam NM, Arman AC, Prusky GT, Sampath AP, Hattar S (2010) Rod photoreceptors drive circadian photoentrainment across a wide range of light intensities. Nat Neurosci 13:1107-1112.

Bailes HJ, Lucas RJ (2010) Melanopsin and inner retinal photoreception. Cell Mol Life Sci 67:99-111.

Belenky MA, Smeraski CA, Provencio I, Sollars PJ, Pickard GE (2003) Melanopsin retinal ganglion cells receive bipolar and amacrine cell synapses. J Comp Neurol 460:380-393.

Berson DM, Dunn FA, Takao M (2002) Phototransduction by retinal ganglion cells that set the circadian clock. Science 295:1070-1073.

Brown TM, Gias C, Hatori M, Keding SR, Semo M, Coffey PJ, Gigg J, Piggins HD, Panda S, Lucas RJ (2010) Melanopsin contributions to irradiance coding in the thalamo-cortical visual system. PLoS Biol 8:e1000558.

Brown TM, Wynne J, Piggins HD, Lucas RJ (2011) Multiple hypothalamic cell populations encoding distinct visual information. J Physiol 589:1173-1194.

Calderone JB, Jacobs GH (1999) Cone receptor variations and their functional consequences in two species of hamster. Vis Neurosci 16:53-63.

Clarke RJ, Ikeda H (1985) Luminance and darkness detectors in the olivary and posterior pretectal nuclei and their relationship to the pupillary light reflex in the rat. I. Studies with steady luminance levels. Exp Brain Res 57:224-232.

Dacey DM, Liao HW, Peterson BB, Robinson FR, Smith VC, Pokorny J, Yau KW, Gamlin PD (2005) Melanopsin-expressing ganglion cells in primate retina signal colour and irradiance and project to the LGN. Nature 433:749-754.

Dkhissi-Benyahya O, Gronfier C, De Vanssay W, Flamant F, Cooper HM (2007) Modeling the role of mid-wavelength cones in circadian responses to light. Neuron 53:677-687.

Dollet A, Albrecht U, Cooper HM, Dkhissi-Benyahya O (2010) Cones are required for normal temporal responses to light of phase shifts and clock gene expression. Chronobiol Int 27:768-781.

Ekesten B, Gouras P (2005) Cone and rod inputs to murine retinal ganglion cells: evidence of cone opsin specific channels. Vis Neurosci 22:893-903.

Ekesten B, Gouras P (2008) Cone inputs to murine striate cortex. BMC Neurosci 9:113.

Gamlin PD, Zhang H, Clarke RJ (1995) Luminance neurons in the pretectal olivary nucleus mediate the pupillary light reflex in the rhesus monkey. Exp Brain Res 106:169-176.

Govardovskii VI, Fyhrquist N, Reuter T, Kuzmin DG, Donner K (2000) In search of the visual pigment template. Vis Neurosci 17:509-528.

Hattar S, Kumar M, Park A, Tong P, Tung J, Yau KW, Berson DM (2006) Central projections of melanopsin-expressing retinal ganglion cells in the mouse. J Comp Neurol 497:326-349.

Haverkamp S, Wässle H, Duebel J, Kuner T, Augustine GJ, Feng G, Euler T
(2005) The primordial, blue-cone color system of the mouse retina. J Neurosci 25:5438-5445.

Jacobs GH, Williams GA (2007) Contributions of the mouse UV photopigment to the ERG and to vision. Doc Ophthalmol 115:137-144.

Jacobs GH, Williams GA, Cahill H, Nathans J (2007) Emergence of novel color vision in mice engineered to express a human cone photopigment. Science 315:1723-1725.

Lall GS, Revell VL, Momiji H, Al Enezi J, Altimus CM, Güler AD, Aguilar C, Cameron MA, Allender S, Hankins MW, Lucas RJ (2010) Distinct contributions of rod, cone, and melanopsin photoreceptors to encoding irradiance. Neuron 66:417-428.

Li W, DeVries SH (2006) Bipolar cell pathways for color and luminance vision in a dichromatic mammalian retina. Nat Neurosci 9:669-675.

Lucas RJ, Douglas RH, Foster RG (2001) Characterization of an ocular photopigment capable of driving pupillary constriction in mice. Nat Neurosci 4:621-626.

Lucas RJ, Hattar S, Takao M, Berson DM, Foster RG, Yau KW (2003) Diminished pupillary light reflex at high irradiances in melanopsinknockout mice. Science 299:245-247.

Lyubarsky AL, Falsini B, Pennesi ME, Valentini P, Pugh EN Jr (1999) UVand midwave-sensitive cone-driven retinal responses of the mouse: a possible phenotype for coexpression of cone photopigments. J Neurosci 19:442-455.

McDougal DH, Gamlin PD (2010) The influence of intrinsicallyphotosensitive retinal ganglion cells on the spectral sensitivity and response dynamics of the human pupillary light reflex. Vis Res 50:72-87.

Mure LS, Rieux C, Hattar S, Cooper HM (2007) Melanopsin-dependent nonvisual responses: evidence for photopigment bistability in vivo. J Biol Rhythms 22:411-424.

Naarendorp F, Esdaille TM, Banden SM, Andrews-Labenski J, Gross OP, Pugh EN Jr (2010) Dark light, rod saturation, and the absolute and incremental sensitivity of mouse cone vision. J Neurosci 30:12495-12507.

Nathan J, Reh R, Ankoudinova I, Ankoudinova G, Chang B, Heckenlively J, Hurley JB (2006) Scotopic and photopic visual thresholds and spatial and temporal discrimination evaluated by behavior of mice in a water maze. Photochem Photobiol 82:1489-1494.

Nikonov SS, Daniele LL, Zhu X, Craft CM, Swaroop A, Pugh EN Jr (2005) Photoreceptors of Nrl-/- mice coexpress functional S- and M-cone opsins having distinct inactivation mechanisms. J Gen Physiol 125:287-304.

Nikonov SS, Kholodenko R, Lem J, Pugh EN Jr (2006) Physiological features of the S- and M-cone photoreceptors of wild-type mice from singlecell recordings. J Gen Physiol 127:359-374.

Okoyama S, Moriizumi T (2001) Onset of calbindin-D 28K and parvalbumin expression in the lateral geniculate complex and olivary pretectal nucleus during postnatal development of the rat. Int J Dev Neurosci 19:655-661.

Panda S, Provencio I, Tu DC, Pires SS, Rollag MD, Castrucci AM, Pletcher MT, Sato TK, Wiltshire T, Andahazy M, Kay SA, Van Gelder RN, Hogenesch JB (2003) Melanopsin is required for non-image-forming photic responses in blind mice. Science 301:525-527.

Paxinos G, Franklin KBJ (2001) The mouse brain in stereotaxic coordinates, Ed 2. New York: Academic.

Pennesi ME, Lyubarsky AL, Pugh EN Jr (1998) Extreme responsiveness of the pupil of the dark-adapted mouse to steady retinal illumination. Invest Ophthalmol Vis Sci 39:2148-2156.

Provencio I, Foster RG (1995) Circadian rhythms in mice can be regulated by photoreceptors with cone-like characteristics. Brain Res 694:183-190.

Puller C, Haverkamp S (2011) Bipolar cell pathways for color vision in nonprimate dichromats. Vis Neurosci 28:51-60.

Röhlich P, van Veen T, Szél A (1994) Two different visual pigments in one retinal cone cell. Neuron 13:1159-1166.

Sampath AP, Strissel KJ, Elias R, Arshavsky VY, McGinnis JF, Chen J, Kawamura S, Rieke F, Hurley JB (2005) Recoverin improves rod-mediated vision by enhancing signal transmission in the mouse retina. Neuron 46:413-420.

Schmidt TM, Kofuji P (2010) Differential cone pathway influence on intrin- 
sically photosensitive retinal ganglion cell subtypes. J Neurosci 30: 16262-16271.

Schmidt TM, Taniguchi K, Kofuji P (2008) Intrinsic and extrinsic light responses in melanopsin-expressing ganglion cells during mouse development. J Neurophysiol 100:371-384.

Smallwood PM, Olveczky BP, Williams GL, Jacobs GH, Reese BE, Meister M, Nathans J (2003) Genetically engineered mice with an additional class of cone photoreceptors: implications for the evolution of color vision. Proc Natl Acad Sci U S A 100:11706-11711.

Szél A, Röhlich P, Caffé AR, Juliusson B, Aguirre G, Van Veen T (1992) Unique topographic separation of two spectral classes of cones in the mouse retina. J Comp Neurol 325:327-342.

Trejo LJ, Cicerone CM (1984) Cells in the pretectal olivary nucleus are in the pathway for the direct light reflex of the pupil in the rat. Brain Res 300:49-62.

Tu DC, Zhang D, Demas J, Slutsky EB, Provencio I, Holy TE, Van Gelder RN (2005) Physiologic diversity and development of intrinsically photosensitive retinal ganglion cells. Neuron 48:987-999.

von Schantz M, Argamaso-Hernan SM, Szél A, Foster RG (1997) Photopigments and photoentrainment in the Syrian golden hamster. Brain Res 770:131-138.

Wong KY, Dunn FA, Graham DM, Berson DM (2007) Synaptic influences on rat ganglion-cell photoreceptors. J Physiol 582:279-296.

Yao G, Zhang K, Bellassai M, Chang B, Lei B (2006) Ultraviolet lightinduced and green light-induced transient pupillary light reflex in mice. Curr Eye Res 31:925-933. 